\title{
Distinguishing Features of Funds of Knowledge, Curriculum of Lives, Habitus, and Discourses
}

\author{
Mary Rice
}

\begin{abstract}
This paper explores the affordances and limitations of several popular conceptual frameworks often used in qualitative literacy research, especially that where narratives are used as data. These frameworks are Funds of Knowledge, Curriculum of Lives, Habitus, and Discourses. The author draws on the narratology of Bal to open space for comparing these frameworks, and through a sample analysis of one narrative, exposes underlying assumptions the frameworks reveal about relationships in research, literacy, and narrative analysis.
\end{abstract}

\section{Introduction}

Distinguishing Features of Funds of Knowledge, Curriculum of Lives, Habitus, and Discourses

I just wish you all could understand how many shots I took to make what came out to be like a 10-minute film. And it wasn't that they were not good shots, some of them were, but they just did not tell the story the way I wanted to tell it. (Alan, reconstructed field note, 2008)

This field text comes from a presentation made by Alan, a then-15-year-old boy whose literate identity I was inquiring into (Rice, 2011a). The film he made for his class was based on a folktale in a picture book that I had given Alan to read the year before. He loved the book and decided to marshal his resources-including the neighborhood children, his family, and other members of his class-to produce a cinematic version of the picture book. While I was analyzing this text, I struggled to decide which methodological lens to apply to this text and to my study on a larger scale. Like Alan, I believed that I had many good "shots" of narrative data from which I could choose to try to tell the story of Alan's literacy. However, I also wanted to attend to telling the story in a way that honored the boys and their families and would render Alan's story optimally powerful. When I realized this goal, it became necessary to carefully examine several analytical lenses through which the shots of Alan's literacy might be viewed before coming to a decision.

As a qualitative researcher, one of my major academic curiosities lies in classrooms-complete with educators and children, and parents, and others-as living ecologies. With such an interest, I was drawn to multiple tools from multiple programs of research for describing ways of knowing, living, and interacting on and 
between home, school, and community landscapes. The tools ${ }^{1}$ that were often cited in the work that I was reading were Funds of Knowledge (Moll, Amanti, Neff, \& Gonzalez, 2001), Curriculum of Lives (Clandinin et al., 2006), Habitus (Bourdieu \& Johnson, 1993) and the capital that accompanies it (Bourdieu, 1986), and Discourses (Gee, 2007). As I moved forward in my scholarly work, I became interested in distinguishing between these four conceptualizations. I desired to understand more fully the work of others, to avoid confounding these tools in my own work, and as I mentioned earlier, so that the stories I used as research texts would garner narrative resonance (Conle, 2010), or some optimal degree of fidelity. In other words, I wanted to trust the work of others and give my own commensurate confidence.

\section{Setting the Purpose for this Paper}

The purpose of this paper is to demonstrate the methods I used to consider not only the differences in these various approaches, but also to understand the ways in which they overlap. In addition to the tools that I considered for analyzing Alan's narrative of his literacy, I found it helpful to use one additional lens to make visible the limitations and affordances of the tools. The lens that assisted me in this analysis is based on the work of Bal (2009), who proposed stories that represent the perspectives of narrators, characters, and actors.

In Bal's (2009) work, a narrator is a connected to a focalizer, or element, which has a point-of-view. The narrator determines who or what the focalizer will be. Although there are some conceptions of grammar that allow for first-person, second-person, and third-person narrators, for Bal, there is only first person. The narrator need not be directly in the narrative. But even a sentence where the pronouns he and she are used comes from a first-person narrator telling the story through a linguistic narrative agent. A narrative agent is some type of text. A character is always directly in the narrative. In fact, the characters are the specific anthropomorphic figures that the narrator tells about. An actor, in contrast to a character's specificity, is general. Actors either cause or undergo events. An event, according to Bal, is a transition from one state, frame, or way of being to another. In a narrative, the character, narrator, and actor can all be the same figure. They can also all be different figures.

In using a storied approach to interpret and discuss these four lenses, I am able to take into account the shifting nature of participants in research whose knowledge and experiences are captured using these tools. I am also able to put together a research story of the interactions between these tools and the data, which is often qualitative or storied in form, particularly in the work that I do as an academic. This paper is neither an attempt to malign nor to exalt any of these conceptual tools. Rather, it is a rationalization for how I came to understand the

\footnotetext{
${ }^{1}$ These tools are also referred to as conceptual tools, conceptual frames, conceptual lenses, or simply tools, frames or lenses in various studies and handbooks. I have also seen them referred to as programs of research, approaches, orientations, concepts, perspectives, and even notions. I mostly use the terms frame and tool with or without the word conceptual throughout the paper.
} 
nuances of them in my own work, which mainly engages with narrative forms of data.

The following is an explanation of the conceptual tools that are the focus of this article. The researcher(s) or theorist(s) who initially conceptualized each one, as well as the methodologies with which the programs of research are associated, will identify each tool.

\section{Funds of Knowledge (FoK)}

The Funds of Knowledge program of research grew out of the work of Moll, Amanti, Neff, and Gonzalez (2001). These researchers developed this conceptual tool not only as a way to organize findings, but also as a method for obtaining them. FoK research was developed specifically for the field of education, with particular attention to teacher preparation and teacher development, although the concepts may transfer to other professions where working with families is essential. In FoK research, teachers form curriculum inquiry groups and schedule visits to families in the communities where they teach. The families are visited and teachers take ethnographies of the households that include inquiries into family work history, recreational interests and other types of knowledge necessary for family survival, especially economic survival, in the community. The aspects of culture that were uncovered, which may prove valuable to understanding how the visited students might make more efficient use of curricular concepts as a result of probing these topics, are referred to as FoK. The teachers return from their series of ethnographically motivated home visits to meet together to plan curricula based on the FoK they identify. In a strict FoK study, the curriculum developed using a FoK approach is then enacted in the classrooms of the teachers who made the visits and designed the instruction. In a variation of FoK studies, teacher candidates conduct the ethnographic interviews to learn more about diverse families, and then they design curriculum for a class that is not their own. In one FoK study, a teacher realized that her students' lives were all connected to the mining industry, and so she built a curriculum around mining to teach the other subject areas in her class. In another study, a teacher used understandings from mothers who sew to teach mathematic concepts (Moll, et. al, 2001).

\section{Curriculum of Lives (CoL)}

The Curriculum of Lives conceptual frame (Clandinin, Huber, Huber, Murphy, Murray-Orr, Pearce \& Steeves, 2006) has several historical roots. Not all of these are directly related to educational research, but for the purpose of this paper, I will discuss those that are relevant to the development of CoL as a tool for looking into classrooms. Clandinin and Connelly (1992) suggested that teachers' and students' lives together in schools merge to form curriculum. These researchers developed that notion from Dewey's (1938) argument that situations and experiences contribute, or ought to contribute, to an overall education. Complementing Dewey's work, Schwab (1970) described actions in the classroom as being built around what he called curricular commonplaces. These commonplaces are teacher, learner, 
subject matter, and milieu. These four entities merge around an activity, the result of which is a curriculum of lives where storied lives are composed, recomposed, shaped, and shifted across the elements of place, time, inward and outward, and social, which form the three-dimensional narrative space (Clandinin \& Connelly, 2000).

As teachers and students in a community live in school and live out stories about them, their lives, and the subject matter they are studying, curriculum is made, and so are lives. This frame assumes that teachers are not the only curriculum makers in a classroom. Indeed, both children (Clandinin et al., 2006) and parents are active and direct makers of curriculum both formally and explicitly, and informally and implicitly. Huber, Murphy, and Clandinin (2011) looked at Ji-Sook's familial curriculum where she could not have a birthday party unless she achieved at a certain level in school. It is rare for teachers to be aware of such curricula, yet this curriculum causes both healthy and unhealthy tension for children as they travel between their worlds of home and school (Lugones, 1987).

\section{Habitus and Concomitant Capital}

Social classes form habitus, which are ways of being, which they reproduce to varying degrees of consciousness in order to assert social prominence (Bourdieu \& Johnson, 1993). This frame does not have its origins in the field of education specifically, but rather in general sociology. Beginning in childhood, young people are apprenticed into the habitus of their respective class. The focus on resources is purely economic, but encapsulates cultural ones as well. Bourdieu (1986) called the resources that grow out of and alongside habitus forms of capital. He defines capital as "assets that are available for use in the production of further assets" (p. 241).

Bourdieu identifies three forms of capital: economic capital, or that which directly converts to money; social capital, a network of relationships with other people that can potentially be mobilized for social advancement; and cultural capital, or forms of knowledge that will give an individual higher status in society. Cultural capital, according to Bourdieu (1986) subdivides into three types. The first type is embodied capital, which is the inherited, automatic, or nonconscious (Stern, 2004) knowledge that a person has to meet their needs. This type of capital becomes part of a person's character and way of thinking. The second type is objectified cultural capital. People with objectified cultural capital own things that other people recognize as being valuable. The final type is institutionalized cultural capital, such as academic credentials or qualifications.

The differences between cultural capital and social capital are subtle. Kang and Glassman (2010) propose that cultural capital is moral thought, or knowing the moral rules of a social situation, and social capital is moral action that garners trust in the community. This paradigm for connecting thought and action is helpful for determining the difference between cultural and social capital, especially when one exists without the other or when there is an obvious difference in quality or quantity between the two in a given situation. 
In places like school, children could have their habitus, and the capital that comes with it, validated, which positions them to display and produce further capital. However, it is also possible that the habitus children possess is not the kind that produces socially sanctioned capital. When students display aspects of a nondominant habitus, they are at risk of being subjected to symbolic violence (Bourdieu, 1987). In this scenario, ways of being that are not seen as prestigious are rejected, often implicitly but sometimes explicitly as well. The potential capital from the rejected habitus eventually ceases to exist, since it cannot be used to produce further assets. Hamston and Love (2005) conducted a study on the cultural practices of boys who claimed to like reading but were resistant to school reading tasks. This study articulated the boys' interpreted rejection of the middle class habitus embodied in school reading practices.

\section{Discourse}

The conceptualization of Discourse grew out of understandings about habitus and capital. James Gee, a philosopher and linguist who eventually turned his interests toward education, is renowned for exploring this concept. According to Gee (2007), part of belonging to a larger community of Discourse is participating in the literacies that form the habitus (Bourdieu \& Johnson, 1993) of that group. He distinguished Discourse with an upper-case $D$ from discourse in lower case. With a small $d$, discourse refers to the metaconversation occurring among speakers. Discourse, on the other hand, is about the ability to leverage the cultural capital that emerged from habitus through literacy processes, to sound like a full-fledged member of a particular community. Humans, Gee notes, often belong to multiple Discourses. He even proposed Discourse as a lens through which identity-making processes can be analyzed in research (Gee, 2001). Finders's (1997) study focusing on the hidden literacies of adolescents girls also represented a Discourses approach, since she wanted to document which literacies the girls used might transfer into situations outside their friendship groups.

\section{Comparing the Tools Using Teacher Positioning Differences}

This discussion will now turn back briefly to young Alan and the story fragment that appeared at the beginning of this paper. Since I was Alan's teacher in addition to being a researcher, I was interested in how I was positioned as researcher and teacher using each of these tools. I was also struck, as I read about these tools, by how the differences in teacher positioning offered some of the first insights I gained into clarifying what distinguishes the lenses from each other. As I considered these various positions, I was able to undercover some critical differences between the tools that led to further disentanglement using Bal's (2009) work. The purpose of this section is to use the simpler explanation of teacher positioning differences to compare the profiled theoretical lenses before moving into a further, more complicated explanation of differences by identifying narrator, character, and actor. Understanding the differences in teacher positioning may also assist researchers in deciding which lens to employ in a particular study with a particular research question or resulting from particular patterns in collected data. 
FoK requires that the person(s) involved in uncovering positions have practice or the strong potential for practice. Therefore, a FoK approach positions the teacher powerfully. The primary purpose is not to produce a research article, although researchers do write about this work. In the purest form of FoK, teachers go into the homes of children they teach. They have to look more broadly at the experiences in the home so that they can produce usable knowledge for their current context. The FoK methodology was developed to help teachers use children's and families' existing knowledge to bridge to new knowledge and skills, thus meeting the goals of the school by supporting the children in learning. The teacher makes all of the decisions about which cultural knowledge collected during the home visits to take up as curriculum.

In contrast to FoK, much of the CoL may be barely visible in the school classroom. In COL, the frame is the home. Everything in school is contextualized to meet the goals of the home. Some recent work in CoL (e.g., Huber, Murphy \& Clandinin, 2011) also builds on the notion that children are world travelers between curricula of home and curricula of school (Lugones, 1987). Those who conduct this work are most interested in the tensions that arise for the children who are doing the traveling and the parents who are trying to understand the curriculum of school, rather than how the teachers who are working with the children make sense of those travels.

Unlike FoK and CoL, habitus was not intended as a practical argument. In a practical argument, action is always the end (Kirszner \& Mandell, 2010). When Bourdieu discussed habitus, he was merely offering a way to describe the ways in which people developed intangible aspects of culture that could also be used as means of exchange. Uncovering habitus requires the narrator of the findings in a research project to examine the ways in which people use capital across a broader range of social groups. A teacher using a lens of habitus is an arbiter of habitus, and the students are vulnerable to acceptance of that habitus or rejection by the school culture, often represented by the teacher. Although eliminating the presence of any dominant habitus seems impractical, Delpit (1988) recommended that teachers embrace the cultural capital they have in recognizing and structuring habitus so that they can make sure they explain the rules of the dominant habitus and reduce the symbolic violence about which Bourdieu (1987) warned. In a habitus stance, a teacher is the holder of cultural capital that is either used to develop social capital, or trust with the students, or plays out in the landscape of school as symbolic violence.

Since the notion of Discourses (Gee, 2007) is highly related to the notion of habitus, these ideas share the potential for moving across a range of social groups. As a result, the classroom is automatically diminished. Indeed, the classroom is often referred to as a Secondary Discourse. Studies that focus on Discourse as an interpretation lens often conclude that the classroom is the environment that must be altered accommodate the Primary Discourses and thus, the assumption is that teachers must change their practices. Since research that employs the lens of Discourses assumes that teachers are disconnected from the primary discourses of 
their students, they are positioned weakly and even negatively if they are too disconnected from their school site and their students. In an example of how teachers could or should take up Discourses, Gee (2007) has focused on how the Discourse of video games deserves more space in classroom learning. Studies based on this aspect of Gee's work focus on how teachers make space for this Discourse.

\section{Interpreting Alan's Story}

This section turns once again to Alan's story that began this article. The interpretive accounts of his story will be filtered through the lenses of each of the tools that have been profiled in this article (FoK, CoL, Habitus, Discourses) using character, actor, and narrator as the apparatus for organizing the interpretation in each of the frames. For reading convenience, Alan's story is reinserted in the text.

I just wish you all could understand how many shots I took to make what came out to be like a 10-minute film. And it wasn't that they were not good shots, some of them were, but they just did not tell the story the way I wanted to tell it. (Alan, reconstructed field note, 2008)

\section{FoK}

In a FoK approach, families and communities take on roles as characters in the narratives that emerge. They can also be the actors, but a teacher in an ethnographic stance narrates the findings. When the teacher makes home visits, comes to new understandings, or begins to build curriculum, this constitutes an event that the teacher experiences. In Alan's story, as an ethnographer looking at how Alan's story reveals the ways in which his family manages its economic resources, I would look to see if his parents were also involved in film. As it turns out, his father has done extensive filming as part of his employment. Part of my FoK approach then might involve inviting Alan's father to help my classes make films. As an ethnographer, I would also be concerned about whether filming was a practice undertaken by others in Alan's class and neighborhood. If it were, then it would garner even more attention, and other families who also filmed might be sought out and visited.

As I made my move from ethnographer to teacher, I would look at the story for ways that the FoK of filming might help Alan make sense of various subject areas. I could interview his father further to uncover the ways that he uses various skills in order to produce visual text. I would consider which of these skills might help me construct curriculum in order to teach my subject matter. How could film production reveal understandings about math, science, history, and literature? Alan was explicit about the fact that he carefully selected shots to incorporate into a final project. This understanding might yield critical insights for talking about how to engage in process writing in school. It also might help me, as his teacher, to design contextualized ways to open conversations about the representation and misrepresentation of groups historically in a text by suggesting that other people with various interests had also been selective about what they chose to include in official instructional materials like textbooks. 


\section{CoL}

In a shift from the FoK approach, when researchers are using a CoL, families and children also share the dual roles of characters and actors in stories. However, researchers who engage in CoL make strategic, deliberate attempts to represent the research in ways to help them argue that the children are the narrators of the stories. The researcher as narrator may make appearances as a character or actor of secondary importance.

When a CoL interpretation is applied to Alan's story, the focus shifts from Alan's father and ethnographic understandings of how subject matter knowledge is used outside of school, to the tensions Alan may be experiencing. These tensions may emerge because Alan wanted to do a film project, which is possible and even easy to do on his home landscape, but difficult to achieve as he travels from the world of home to the world of school. When researchers engage with Alan's story using CoL, they might wonder about how this experience served as emblematic narrative for other aspects of his literacy or participation in school. Besides a metaphor of world traveling, they might look at the fact that Alan needed almost a full year to do this particular project and wonder if this might cause tension in a school environment where impulsiveness is rewarded over reflectivity.

Any text that might be constructed would be negotiated with Alan in a setting where he would have the opportunity to talk about the experience of conducting his film project and selecting shots that would allow him to honor his home landscape and bring him success on the school one. The ethical relationship between Alan as a student and me as a teacher who now can assert insight about Alan's need to work thoughtfully for an extended period of time might also be discussed. Thus, a CoL approach not only implies the identification of tensions; the health of those tensions is also an object of study. Like FoK, a CoL approach involves the home and the school, but the object is not to bring those two worlds together, but rather to watch and marvel at their interaction.

\section{Habitus}

A habitus frame would be interested in narrating the findings from Alan's story in such a way as to raise issues about how the practice of filming operates as cultural capital, where Alan is recognized as important for having access to the skills and equipment necessary to film. The fact that he was able to use these skills and other aspects of his cultural capital to enlist others in helping him make the film demonstrates that he can leverage the trust that is social capital. His desire to pick just the right shots also demonstrates a social astuteness where he realizes that certain configurations of shots will make his product look more legitimate, earning him the trust of his neighbors.

In a habitus frame, it would also be worth noting that Alan lives in an organized neighborhood where the individual families are sufficiently familiar with each other to trust Alan in assisting him in his project. Putnam (2001) would stretch the idea of capital slightly further by suggesting that Alan and/or his family have generalized reciprocity with those who live near them. One might even speculate 
that Alan's parents have particular roles which make their family visible and from which Alan benefits. Thus, Alan and his family become bearers of the habitus of their community or unwitting accomplices in symbolic violence (Bourdieu, 1987) if Alan's films are valued over other children's ways of constructing, sharing, and presenting knowledge to groups.

In the end, the questions of habitus center on questions of value that lend themselves to explanation or critique. In a FoK approach, value is also considered, but leveraging the cultural capital in the classroom is the goal. The CoL approach also cares about tension, but the focus is on the tension of the child as he negotiates a curriculum at home and at school, instead of tension between groups of haves and have-nots.

\section{Discourses}

In the Discourses frame, specific members, or hopeful members, of primary and secondary Discourses are the characters in the research narratives. There are also general actors that undergo or cause events in these narratives. In educational research, the central characters often undergo events that are caused by members of primary and secondary discourses while the researcher openly narrates these events. In a Discursive interpretation of the text, Alan is the actor in a primary Discourse that he brought into a Secondary Discourse. Alan is a person who would like to be a member of the Discourse of cinematographers. He is making attempts to join this Discourse by engaging in several behaviors, which include searching for subject matter, locating actors, organizing a set, taking footage, editing footage, and finding audiences for his final product.

Those who conceptualize literacy into Primary Discourses of home and Secondary Discourses of school might praise the fact that I allowed Alan to show the film in class. Even so, a narrator of Discourse in research might also be concerned about the fact that I was not developing the Discourses of the other students because I could not teach them how to make films like Alan had learned to do. In melding the idea of Discourses and habitus, critique may arise about whether Alan was allowed to pursue the Discourse of film while other students' Discourses or desires to attain Discourses were not attended to at the same level. Since the Discourse of film carries with it some notions about reading pictures and critical literacy, a narrator using a Discourse frame might shift the conversation into one about disciplinary literacy (Lee, 2007) and using the skills of critical visual literacy in more efficacious ways than I may already be doing.

The individual activities in which Alan is engaging also represent attempts to enact the individual literacies that make up the habitus of the filmmaking Discourse. With a FoK orientation, Alan's filmmaking serves as a starting point for investigating whether his father has a career or recreational interest in film. Using Discourse as the primary tool, Alan's filmmaking is about whether others who are already in that Discourse could ever accept him as a full-fledged cinematographer. The Discourse lens, and the habitus from which is it derived, do not allow very much space for people to declare their own literacies. FoK calls the economically valuable literacies 
Funds. A Fund can be spent like capital, and therefore someone else has to recognize it. In contrast, a CoL frame allows a person to both call himself and be called literate, since the focus is on what people do as they negotiate and build identities on various landscapes.

\section{Drawing Conclusions about the Tools}

In examining these tools, first from a simpler teacher positioning perspective, and then from a more complex character, actor, narrator analytical perspective, several implications come into view. The first implication is a practical one of audience in writing and reporting qualitative research, particularly where narratives are used as data. The second is a more complicated implication about methodological possibilities for qualitative research.

\section{Practical Implications of Audience}

The audience to which I wish to present my work about Alan's literacy will inform which of the four lenses (and of course, there are others) I might use to interpret this narrative in context. By employing FoK, I assume that my audience cares about curriculum making, based on what I can determine about Alan's economic home culture. If I use CoL, I assume the people who read my work with be interested in the tension of Alan's need to embark on long-term projects in a school system that rarely makes space for that. A habitus analysis serves readers who want to know about the status of Alan's family because of the films he made and the potential for access that other groups have. An audience inclined towards Discourse is prepared to hear about Alan's identity as a filmmaker as it develops across his various projects, and whether his teachers provided ways to support him and others in developing similar positive identities.

While researchers are advised to determine which methods and tools of analysis to use based on research purposes and questions (Creswell, 2011), a host of other factors push on the researcher to generate certain questions or use certain theoretical lenses. A researcher's own comfort or experience with one of the tools may cause an analysis to come easier from that frame. A funded project might demand a certain form of analysis be used in order to demonstrate whether large quantities of money used to conduct the research were used wisely. The interest in the teacher, the subject matter, the learners, or the milieu will also influence the type of lens used.

\section{Methodological Implications for Qualitative Research}

Since multiple frames can be used in analysis, several possibilities open up for developing richer qualitative methods. One possibility is to layer the analysis with the resonant pieces of both frames. In this configuration, a separate analysis could first be conducted through each frame, and then the overlapping pieces could determine the findings. I conducted such an overlapping process when I studied the narratives of food-giving that took place in my junior high classroom (Rice, 2011b). In the present paper, I overlaid Bal's (2009) work over each of the tools to produce 
varying insights, since I wanted to examine each of the tools as if they were narratives about how research can be analyzed and interpreted. What I did was take one boy's story, overlay it with Bal's tool, and then superimpose each of the tools in turn while comparing and contrasting them to produce as many pathways of insight into Alan's literacy as I could.

The analytical insights that overlap might be judged as having more narrative resonance (Clandinin, Pushor, \& Murray Orr, 2007) because these insights develop across more than one analytical tool. Another way to shape findings might be to focus on the outlying insights that emerge during an overlapping process. These nonaligning findings may be the ones that resonate as unique contributions because they only emerge in one frame. The insights that emerge during the overlapping process-be they compound or singular-might lead to new insights on research projects for researchers looking at both new data and projects previously published.

\section{References}

Bal, M. (2009). On narratology: Introduction to the theory of narrative, $3^{\text {rd }}$ ed. Toronto: University of Toronto Press.

Bourdieu, P. (1986). The forms of capital. In J. B. Richardson (Ed.), Handbook of theory and research in the sociology of education. New York: Greenwood Press.

Bourdieu, P. (1987). Distinction: A critique of taste. Cambridge, MA: Harvard University Press.

Bourdieu, P. \& Johnson, R. (1993). The field of cultural production. New York: Columbia University Press.

Clandinin, D. J., \& Connelly, F. M. (1992). Teacher as curriculum maker. In P. Jackson (Ed.), Handbook of research on curriculum (p. 364-401). Toronto: MacMillan.

Clandinin, D. J., \& Connelly, F. M. (2000). Narrative inquiry: Experience and story in qualitative research. San Francisco: Jossey-Bass.

Clandinin, D. J., Huber, J., Huber, M., Murphy, M. S., Murray-Orr, A., Pearce, M., \& Steeves, P. (2006). Composing diverse identities: Narrative inquiries into the interwoven lives of children and teachers. London: Routledge.

Clandinin, D. J., Pushor, D., \& Murray Orr, A. (2007). Navigating sites for narrative inquiry. Journal of Teacher Education, 58(1), 21-35.

Conle, C. (2010). Practice and theory in narrative inquiry. London: Routledge.

Creswell, J. W. (2011). Educational research: Planning, conducting, and evaluating quantitative and qualitative research, $4^{\text {th }}$ ed. Boston: Pearson.

Delpit, L. (1988). The silenced dialogue: Power and pedagogy in teaching other people's children. Harvard Educational Review, 58(3) 280-298.

Dewey, J. (1938). Experience and education. New York: Kappa Delta Pi Publications. 
Finders, M. J. (1997). Just girls: Hidden literacies and life in junior high. New York: Teachers College Press.

Gee, J. P. (2001). Identity as an analytic lens for research in education. Review of Research in Education, 25, 99-125.

Gee, J. P. (2007). Social linguistics and literacies: Ideology in discourses, $3^{\text {rd }}$ ed. New York: Taylor and Francis.

Hamston, J., \& Love, K. (2005). Voicing resistance: Adolescent boys and the cultural practice of leisure reading. Discourse Studies in the Cultural Politics of Education 26, 183-202.

Huber, J., Murphy, S., \& Clandinin, D. J. (2011). Places of curriculum making: Narratives into children's lives in motion. Bingley, UK: Emerald Press.

Kang, M. J., \& Glassman, M. (2010). Moral action and social capital, moral thought as cultural capital. Journal of Moral Education, 39(1), 21-36.

Kirszner, L. G., \& Mandell, S.R. (2010). Practical argument: A text and anthology. New York: Bedford/St. Martin's.

Lee, C. D. (2007). Culture, literacy, and learning: Blooming in the midst of the whirlwind. New York: Teachers College Press.

Lugones, M. (1987). Playfulness, "World" Travelling, and Loving Perception. Hypatia, 2, 3-19.

Moll, L., Amanti, C., Neff, D., and Gonzalez, N. (2001). Funds of knowledge for teaching: Using a qualitative approach to connect homes and classrooms. Theory Into Practice, 31(2), 132-141.

Putnam, R. (2001) Social Capital: measurement and consequences. Isuma 2, 41-51.

Rice, M. (2011a). Adolescent boys' literate identity. Bingley, UK: Emerald Press.

Rice, M. (2011b). The edible gifts they carried: Food gifts from junior high students. Presented at the Narrative Research Works in Progress Conference, Sept. 2011, Anchorage, Alaska.

Stern, D. (2004). The present moment in psychotherapy and real life. New York: Norton. 


\section{Appendix}

\begin{tabular}{|c|c|c|c|}
\hline & $\begin{array}{l}\text { Who narrates the } \\
\text { findings in this } \\
\text { program of research? }\end{array}$ & $\begin{array}{l}\text { Who are the } \\
\text { characters in the } \\
\text { narratives of this } \\
\text { program of } \\
\text { research? }\end{array}$ & $\begin{array}{l}\text { Who are the actors in the } \\
\text { narratives that emerge in } \\
\text { this program of research? }\end{array}$ \\
\hline $\begin{array}{l}\text { Funds of } \\
\text { Knowledge }\end{array}$ & $\begin{array}{l}\text { Teachers in an } \\
\text { ethnographic stance }\end{array}$ & $\begin{array}{l}\text { Specific members of } \\
\text { families and } \\
\text { communities }\end{array}$ & Families and teachers \\
\hline $\begin{array}{l}\text { Curriculum of } \\
\text { Lives }\end{array}$ & $\begin{array}{l}\text { Children-mediated } \\
\text { through researchers }\end{array}$ & $\begin{array}{l}\text { Specific families and } \\
\text { children }\end{array}$ & $\begin{array}{l}\text { Families, children, and } \\
\text { teachers }\end{array}$ \\
\hline Habitus & $\begin{array}{l}\text { Anyone-teachers, } \\
\text { researchers, politicians, } \\
\text { since narration in this } \\
\text { stance occurs outside of } \\
\text { formal research-who } \\
\text { has cultural capital }\end{array}$ & $\begin{array}{l}\text { Specific members of } \\
\text { social groups }\end{array}$ & $\begin{array}{l}\text { General members of social } \\
\text { groups and/or the } \\
\text { characters }\end{array}$ \\
\hline Discourses & Researchers & $\begin{array}{l}\text { Members, or hopeful } \\
\text { members, of Primary } \\
\text { and Secondary } \\
\text { Discourses }\end{array}$ & $\begin{array}{l}\text { Individual members or } \\
\text { hopeful members of } \\
\text { primary and secondary } \\
\text { discourses and institutional } \\
\text { representatives of Primary } \\
\text { and Secondary Discourses }\end{array}$ \\
\hline
\end{tabular}

